\title{
COEFICIENTE DE DISTRIBUIÇÃO DO INSETICIDA TIAMETOXAM NA FRAÇÃO MINERAL DE SOLOS SOB EFEITO DE ÁCIDOS ORGÂNICOS MONO, DI E TRICARBOXÍLICOS
}

\author{
Samara Andrade Carvalho*, José Maria de Lima, Niton Curi, Carlos Alberto Silva, João Paulo Vaz Floriano Toledo e \\ Flávia Villela Soares \\ Departamento de Ciência do Solo, Universidade Federal de Lavras, 37200-000 Lavras - MG, Brasil
}

Recebido em 14/2/13; aceito em 5/6/13; publicado na web em 5/7/13

\begin{abstract}
DISTRIBUTION COEFFICIENT OF THE INSECTICIDE THIAMETHOXAM IN THE MINERAL FRACTION OF SOILS UNDER THE EFFECT OF MONO, DI AND TRICARBOXYLIC ORGANIC ACIDS. The aim of this study was to investigate the sorption and desorption of thiamethoxam in contrasting soils under the effect of organic acids. The results showed that MTo sorption had higher Kd. The presence of organic acids increased sorption and reduced desorption of thiamethoxam at MTo. The opposite was observed for the LVdf where the presence of $400 \mu \mathrm{mol} \mathrm{L} \mathrm{L}^{-1}$ of acid reduced the sorption of thiamethoxam in a concentration of $20 \mu \mathrm{mol} \mathrm{L}{ }^{-1}$, not influencing desorption. The dynamics of organic acids with minerals from the soil particles were clarified by infrared analysis.
\end{abstract}

Keywords: pesticide; distribution coefficient; environmental contamination.

\section{INTRODUÇÃO}

Os benefícios dos agrotóxicos, no sentido de garantir maiores produções agrícolas a custos menores, são inquestionáveis. Porém, com o aumento do uso desses produtos, muitas vezes de forma indiscriminada, aumentaram-se também as preocupações com a contaminação de solos e águas superficiais e subterrâneas, com efeitos danosos sobre os seres humanos e animais.

O Brasil tem uma das maiores evoluções no consumo de defensivos. De acordo com o Sindicato Nacional da Indústria de Produtos para Defesa Agrícola (SINDAG), ${ }^{1}$ a venda total de defensivos no Brasil atingiu US\$ 4,425 bilhões em 2011, 3,8\% mais que em 2010, o que torna o Brasil o maior consumidor de insumos do mundo.

Apesar do uso de agrotóxicos serem de enorme importância na crescente produtividade e qualidade de produtos agrícolas, seu uso intensivo e muitas vezes incorreto vem ocasionando contaminação da atmosfera, do solo, da água superficial e subterrânea, o que representa um grave risco para o meio ambiente..$^{2-4}$

Estudos recentes têm mostrado que a sorção e mobilidade dos agrotóxicos no solo é influenciada por diversos fatores, entre eles a presença de ácidos orgânicos de baixo peso molecular, encontrados em todos os organismos vivos e que possuem um ou mais grupos carboxílicos, por meio dos quais podem interagir com a fração mineral do solo. Dependendo das condições de ionização, do número de grupos carboxílicos e do pH do meio, os ácidos orgânicos podem apresentar cargas negativas que permitem a complexação de cátions metálicos em solução ou a adsorção à superfícies minerais que apresentem cargas positivas. ${ }^{5,6}$

Ácidos orgânicos de baixo peso molecular são produzidos pelas raízes das plantas ou durante a decomposição da matéria orgânica do solo. Ácidos como cítrico, oxálico, tartárico, málico, acético, propiônico, butírico, succínico, fumárico e lático são comumente encontrados na rizosfera ${ }^{7}$ em concentrações que variam entre $1 \mu \mathrm{mol}$ $\mathrm{L}^{-1}$ e $2 \mathrm{mmol} \mathrm{L}^{-1} .8$ Estudos recentes mostram que os ácidos orgânicos, em alguns casos, aumentam a dessorção dos agrotóxicos, aumentando consequentemente sua lixiviação no perfil do solo, o que representa um grave risco ambiental. ${ }^{8}$

\footnotetext{
*e-mail: samaraandrade@yahoo.com.br
}

O tiametoxam, inseticida pertencente a classe dos neonicotinoide, começou a ser comercializado somente em 1998. O composto tem larga atividade inseticida e oferece excelente controle de uma variedade de pragas em várias culturas, especialmente no cafeeiro. O tiametoxam é um composto cristalino e sem cheiro, com ponto de fusão de $139,1^{\circ} \mathrm{C}$. O composto apresenta baixa massa molar $(291,72$ $\left.\mathrm{g} \mathrm{mol}^{-1}\right)$, solubilidade em água relativamente alta $\left(4,1 \mathrm{~g} \mathrm{~L}^{-1}\right.$ a $\left.25^{\circ} \mathrm{C}\right)$ e baixo coeficiente de partição entre octanol e água (Kow $=0,74$ a $\mathrm{pH}$ 6,8). Essas propriedades indicam que o mesmo apresenta baixa sorção aos colóides do solo, sendo que considerável fração do produto aplicado ao solo permanece em solução, podendo ser lixiviada para camadas mais profundas do solo. ${ }^{9}$

Diante do exposto, os objetivos do trabalho foram: i) investigar a sorção do tiametoxam na fração argila de um Latossolo Vermelho distroférrico (LVdf) e Chernossolo Argilúvico Órtico típico (MTo) ii) compreender a dinâmica de ácidos orgânicos mono, di e tricarboxílicos com partículas minerais do solo iii) avaliar a influência destes ácidos orgânicos no coeficiente de distribuição do tiametoxam.

\section{PARTE EXPERIMENTAL}

\section{Caracterização dos solos utilizados}

Foram escolhidos dois solos de características contrastantes, sendo utilizadas a fração argila do horizonte B (camada 40-60 cm de profundidade) de Latossolo Vermelho Distroférrico (LVdf), localizado no município de Lavras (MG), e um Chernossolo Argilúvico Órtico típico (MTo), localizado em São Gabriel, Rio Grande do Sul.

Para obtenção da fração argila, $50 \mathrm{~g}$ de terra fina seca ao ar (TFSA) foram levados ao banho-maria, sendo aquecidos à temperatura de, aproximadamente, $80{ }^{\circ} \mathrm{C}$. Em seguida foram adicionados $1 \mathrm{~mL}$ de $\mathrm{H}_{2} \mathrm{O}_{2}(30 \%)$. Após o abrandamento da reação adicionou-se nova quantidade do reagente e repetiu-se o procedimento até não se observar efervescência. Posteriormente todo material foi transferido para um copo agitador, juntamente com aproximadamente $250 \mathrm{~mL}$ de água destilada $+10 \mathrm{~mL}$ de $\mathrm{NaOH} 0,1 \mathrm{~mol} \mathrm{~L}^{-1}$ e disperso mecanicamente em agitador tipo coqueteleira por $20 \mathrm{~min}$. Após esse período, e removida a fração areia por peneiramento, a suspensão (silte + argila) foi transferida para proveta com capacidade de $1.000 \mathrm{~mL}$, obtendo-se 
a fração argila por sifonamento após o tempo de sedimentação da fração silte, com base na Lei de Stokes.

Após a obtenção da fração argila, as amostras foram colocadas na membrana de diálise para a dissolução de carbonatos e sais solúveis. Em seguida as amostras foram secas em estufa a $60{ }^{\circ} \mathrm{C}$ e trituradas usando gral de ágata.

A fração argila do LVdf foi caracterizada por difratometria de raios-X, (método do pó) utilizando um aparelho Philips, com variação angular de $4-50^{\circ} 2 \theta$, radiação de $\mathrm{CoK} \alpha$ e velocidade de varredura de $1^{\circ} \mathrm{min}^{-1}$. Já para o MTo, a fração argila foi inicialmente saturada com $\mathrm{Mg}^{2+}$ e solvatada com glicerol à temperatura ambiente. Também foi saturada com $\mathrm{K}^{+}$e submetida a tratamentos térmicos por duas horas a 25,110 e $550{ }^{\circ} \mathrm{C}$. A argila foi analisada em lâminas com orientação do material em intervalos de 2 a $20^{\circ} 2 \theta$ e 2 a $40^{\circ} 2 \theta$, com velocidade de varredura de $1^{\circ} 2 \theta \mathrm{min}^{-1}$.

Para a caracterização física dos solos, foi determinada a granulometria, pelo método da pipeta. ${ }^{10}$ Para a caracterização química, foram medidos os teores de cátions do complexo sortivo e superfície específica, matéria orgânica e óxidos no extrato sulfúrico $\left(\mathrm{SiO}_{2}\right.$, $\left.\mathrm{Al}_{2} \mathrm{O}_{3}, \mathrm{Fe}_{2} \mathrm{O}_{3}\right) \cdot{ }^{11}$

\section{Ácidos orgânicos utilizados}

Os ácidos orgânicos que foram utilizados no presente trabalho foram os ácidos quínico, oxálico e cítrico. Estes foram escolhidos de acordo com o tamanho e número de grupos carboxílicos da cadeia carbônica. Todos os ácidos orgânicos utilizados no experimento possuía alto grau de pureza, acima de $98 \%$.

\section{Experimento de sorção}

Em tubos de vidro, foram pesados $3 \mathrm{~g}$ de amostra de cada argila. Em seguida, foram adicionados $5 \mathrm{~mL}$ da solução de $\mathrm{CaCl}_{2}$ $0,01 \mathrm{~mol} \mathrm{~L}^{-1}$ contendo tiametoxam nas concentrações 20 e $40 \mu \mathrm{mol}$ $\mathrm{L}^{-1}$. Posteriormente foram adicionados $5 \mathrm{~mL}$ da solução dos ácidos orgânicos nas concentrações 0,200 e $400 \mu \mathrm{mol} \mathrm{L} \mathrm{L}^{-1}$. O experimento foi conduzido em triplicata. Os tubos foram agitados durante 4 horas para $\operatorname{LVdf}^{12}$ e 24 horas para o Mto, tempo suficiente para a solução entrar em equilíbrio com a argila; em seguida, foram centrifugados a $710 \mathrm{~g}$, por 30 minutos. Foi retirada uma alíquota de $2 \mathrm{~mL}$ da solução aquosa, que foi filtrada em membrana de $0,45 \mu \mathrm{m}$ (PTFE) e armazenada em geladeira para posterior análise utilizando a Cromatografia Líquida de Alta Eficiência (HPLC). A concentração do tiametoxam presente na argila foi calculada pela diferença entre a concentração inicial e a concentração do composto encontrada na fase aquosa após o respectivo tempo de agitação, multiplicada pelo volume de solução e dividida pela massa de solo.

A partir dessa equação calculou-se o coeficiente de distribuição $\left(\mathrm{K}_{\mathrm{d}}\right)$ (equação 1) do composto entre as fases sólida e aquosa para todos os tratamentos:

$K d=\frac{\text { Concentração do composto sorvido ao solo }}{\text { Concentração do composto na solução de equilibrio }}$

Os tratamentos constituíram um delineamento inteiramente casualizado, em esquema fatorial $2 \times 2 \times 3 \times 3$, correspondente a duas classes de solos, duas concentrações de tiametoxam, três ácidos orgânicos, três concentrações de ácido, com três repetições, totalizando 108 parcelas experimentais.

\section{Experimento de dessorção}

Para o estudo da dessorção, a fase aquosa foi retirada logo após a centrifugação, com auxílio de uma pipeta Pasteur; os tubos foram pesados, para se determinar a solução oclusa e, em seguida, foram adicionados $10 \mathrm{~mL}$ da solução de $\mathrm{CaCl}_{2} 0,01 \mathrm{~mol} \mathrm{~L}^{-1}$, retornando os tubos à mesa agitadora, na qual permaneceram por mais 4 e 24 horas, para LVdf e MTo, respectivamente. Após esse tempo, os tubos foram centrifugados a $710 \mathrm{~g}$ por 30 minutos, retirando-se $2 \mathrm{~mL}$ da solução aquosa, que foram filtrados e armazenados em geladeira para posterior análise no HPLC, como descrito para sorção. A quantidade dessorvida do tiametoxam foi analisada na concentração de equilíbrio. A dessorção absoluta foi calculada pela diferença da concentração de tiametoxam presente na argila após a sorção e após a dessorção. A partir dessa equação calculou-se o coeficiente de distribuição $\left(\mathrm{K}_{\mathrm{d}}\right)$ do composto entre as fases sólida e aquosa para todos os tratamentos (equação 1).

$\mathrm{O}$ experimento de dessorção também constituiu de um delineamento inteiramente casualizado, em esquema fatorial $2 \times 2 \times 3 \times$ 3 , correspondente a duas classes de solos, duas concentrações de tiametoxam, três ácidos orgânicos, três concentrações de ácido, com três repetições, totalizando 108 parcelas experimentais.

\section{Condições operacionais do cromatógrafo}

Para determinação quantitativa do tiametoxam foi utilizado o HPLC, modelo HP série 1100, operando com detector de ultravioleta. A coluna utilizada foi uma Ascentis ${ }^{\circledR} \mathrm{C} 18,5 \mu \mathrm{m}, 25 \mathrm{~cm} \times 4,6 \mathrm{~mm}$. Para a quantificação do tiametoxam foi utilizada acetonitrila/água ultra pura como fase móvel, na proporção 20/80 com vazão de $1 \mathrm{~mL}$ $\min ^{-1}$, volume de injeção de $20 \mu \mathrm{L}$ e comprimento de onda de 255 nm. Nessas condições, o tempo de retenção do tiametoxam ficou em torno de 8 minutos.

A quantificação do tiametoxam foi realizada por comparação da área dos picos das amostras com a curva analítica, cuja faixa linear foi de 1 a $35 \mu \mathrm{mol} \mathrm{L}{ }^{-1}$.

\section{Análises ATR-FTIR}

Foram realizados ensaios de sorção e dessorção, com ambas as argilas, contendo apenas os ácidos orgânicos na concentração de $0,5 \mu \mathrm{mol} \mathrm{L}{ }^{-1}$. Após a centrifugação foram retiradas alíquotas de argilas, as quais foram congeladas e liofilizadas até completamente secas. Em seguida as argilas foram maceradas utilizando gral de ágata.

A análise dos grupos funcionais dos ácidos orgânicos presentes na superfície dos minerais foi realizada por espectroscopia na região do vermelho com Transformada de Fourier (FTIR) em aparelho Brucker Vertex $70 \mathrm{~V}$ com faixa espectral de 4000 a $400 \mathrm{~cm}^{-1}$. Para tal foi realizada a técnica de Reflectância Total Atenuada (ATR), na qual se empregou um cristal de seleneto de zinco de múltiplas reflexões. A aquisição dos espectros foi realizada à temperatura próxima de $17{ }^{\circ} \mathrm{C}$ e espectros de referência (background) foram adquiridos diretamente da cela vazia e limpa, sendo que um novo espectro de referência foi coletado a cada amostra, para garantir a qualidade do espectro em relação a variação de $\mathrm{CO}_{2}$, vapores de água presentes na análise e possível variação na linha de base. Cada espectro foi obtido com resolução de $4 \mathrm{~cm}^{-1}$, por meio de 32 varreduras.

\section{Análise estatística}

Foram realizadas análises de variância para os valores de Kd, obtidos no ensaio de sorção e dessorção, sendo realizado um teste de médias (Scott-Knott) a 5\% de significância para comparação entre as médias, utilizando o programa Sisvar. ${ }^{13}$ 


\section{RESULTADOS E DISCUSSÃO}

\section{Caracterização dos solos}

Os difratogramas de Raios-X, a caracterização física, os teores de óxidos pelo ataque sulfúrico e os teores de cátions do complexo sortivo, de ambos os solos, estão apresentados nas Figuras 1 e 2 e Tabelas 1,2 e 3 , respectivamente.

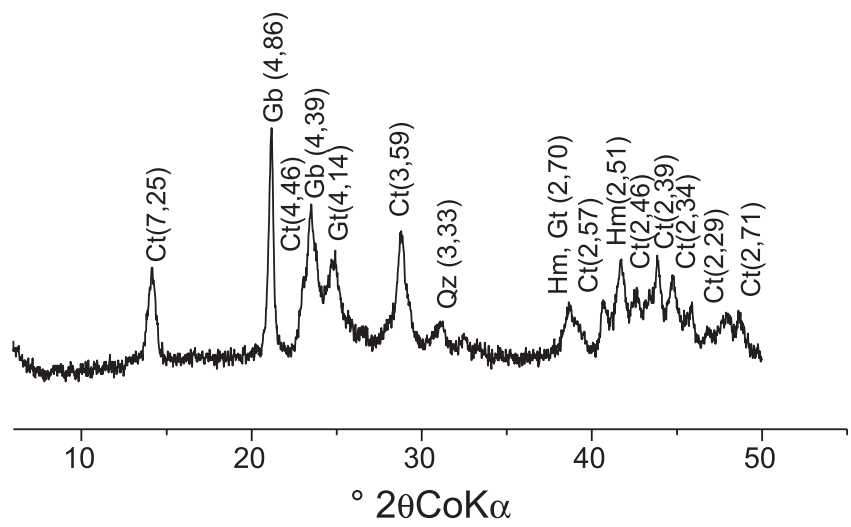

Figura 1. Difratogramas de raio X da fração argila do horizonte $B$ do LVdf. Ct: caulinita, Gb: gibbsita, Gt: goethita, Qz: quartzo, Hm: hematita

A classe dos Latossolos é amplamente difundida no território brasileiro, sendo conhecida pelo seu alto estágio de intemperização que a destitui de minerais menos resistentes ao intemperismo. ${ }^{14}$ Desta forma, possuem mineralogia da fração argila predominantemente formada por minerais silicatados do tipo 1:1 e óxidos de $\mathrm{Fe}$ e Al, dentre os quais podem citar Caulinita, Goethita/Hematita e Gibbsita respectivamente, ${ }^{15}$ conforme visto no difratograma de Raios x (Figura 1).

O LVdf é um solo com altos valores de saturação por alumínio e baixa saturação por base (Tabela 3), possuindo teores elevados de $\mathrm{Fe}_{2} \mathrm{O}_{3}$ (Tabela 2). Possui também textura argilosa (Tabela 1), ocorre em relevo suave ondulado e é um solo bem drenado, profundo, friável ou muito friável.

A partir do método do ataque sulfúrico, que atua principalmente sobre a fração argila, é possível inferir sobre o intemperismo dos solos, baseando-se nos índices $\mathrm{Ki}$ e Kr. Esses índices estão associados ao

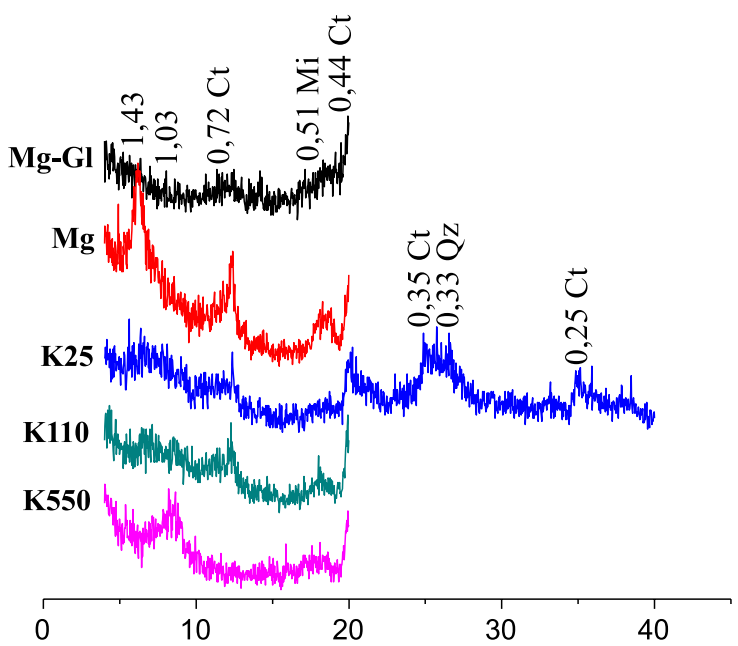

Figura 2. Difratogramas de raios $X$ da fração argila orientada dos horizonte B do MTo. K- saturação com $K$; 550, 110 e $25{ }^{\circ} \mathrm{C}$ - temperatura dos tratamentos térmicos; $\mathrm{Mg}$ - saturação com $\mathrm{Mg} ; \mathrm{Mg}+\mathrm{Gl}$ - saturação com $\mathrm{Mg} e$ solvatação com glicerol

Tabela 1. Caracterização física das amostras do horizonte B de um Latossolo Vermelho distroférrico (LVdf) e um Chernossolo Argilúvico Órtico típico (MTo)

\begin{tabular}{|c|c|c|c|}
\hline \multirow{2}{*}{ Solo } & Argila & Silte & Areia \\
\hline & \multicolumn{3}{|c|}{ - } \\
\hline LVdf & 660 & 170 & 170 \\
\hline MX & 380 & 310 & 310 \\
\hline
\end{tabular}

grau de intemperismo sob um ponto de vista pedológico e, quanto menor for o valor de $\mathrm{Ki}$ e $\mathrm{Kr}$, mais intemperizado será o solo, refletindo desta forma perda de sílica do solo e o aumento dos teores de óxidos de Fe e Al.

Conforme observado na Tabela 2, o valor de Ki para o LVdf é de 0,93 , evidenciando baixa quantidade de minerais silicatados, principalmente devido a facilidade de perda de sílica, dado seu ambiente de formação. ${ }^{16,17}$ Os valores de Ki e Kr para os Latossolos permitem caracterizar a fração argila, quanto a predominância mineral, sendo considerados cauliníticos quando $\mathrm{Ki}>0,75$ e $\mathrm{Kr}>0,75$, cauliníticos

Tabela 2. Teores de óxidos no extrato sulfúrico, índice de intemperismo (Ki e Kr) e teor de matéria orgânica (MO) das amostras do horizonte B de um Latossolo Vermelho distroférrico (LVdf) e um Chernossolo Argilúvico Órtico típico (MTo)

\begin{tabular}{|c|c|c|c|c|c|c|}
\hline \multirow{2}{*}{ Solo } & $\mathrm{SiO}_{2}$ & $\mathrm{Al}_{2} \mathrm{O}_{3}$ & $\mathrm{Fe}_{2} \mathrm{O}_{3}$ & $\mathrm{Ki}^{1}$ & $\mathrm{Kr}^{2}$ & MO \\
\hline & \multicolumn{4}{|c|}{ - } & & dag $\mathrm{kg}^{-1}$ \\
\hline LVdf & 20,11 & 36,66 & 17,72 & 0,93 & 0,71 & 2,70 \\
\hline MX & 38,83 & 29,71 & 9,80 & 2,22 & 1,83 & 1,39 \\
\hline
\end{tabular}

${ }^{1} \mathrm{Ki}\left(1,7 \times \mathrm{SiO}_{2} / \mathrm{Al}_{2} \mathrm{O}_{3}\right) \mathrm{e}^{2} \mathrm{Kr}\left[1,7 \times \mathrm{SiO}_{2} / \mathrm{Al}_{2} \mathrm{O}_{3}+\left(0,6 \times \mathrm{Fe}_{2} \mathrm{O}_{3}\right)\right]$.

Tabela 3. Caracterização química das amostras do horizonte B de um Latossolo Vermelho distroférrico (LVdf) e Chernossolo Argilúvico Órtico típico (MTo)

\begin{tabular}{|c|c|c|c|c|c|c|c|c|c|c|c|c|}
\hline \multirow{2}{*}{ Solo } & \multirow{2}{*}{$\mathrm{pH}^{1}$} & $\mathrm{H}+\mathrm{Al}$ & $\mathrm{K}^{+}$ & $\mathrm{Ca}^{2+}$ & $\mathrm{Mg}^{2+}$ & $\mathrm{Al}^{3+}$ & $\mathrm{SB}^{2}$ & $\mathrm{~T}^{3}$ & $\mathrm{~T}^{4}$ & $\mathrm{~V}^{5}$ & $\mathrm{M}^{6}$ & SE \\
\hline & & \multicolumn{8}{|c|}{ - $\mathrm{cmol}_{\mathrm{c}} \mathrm{dm}^{-3}-$} & \multicolumn{2}{|c|}{$----\%$---- } & $\mathrm{m}^{2} \mathrm{~g}^{-1}$ \\
\hline LVdf & 5,2 & 6,78 & 0,016 & 0,40 & 0,1 & 0,50 & 0,52 & 1,02 & 7,3 & 7,1 & 49 & 71 \\
\hline MX & 5,9 & 6,90 & 0,090 & 11,5 & 7,4 & 1,50 & 18,9 & 20,4 & 25,8 & 73 & 7,3 & 200 \\
\hline
\end{tabular}

${ }^{1} \mathrm{pH}$ em água: relação $(1: 2,5) ;{ }^{2} \mathrm{SB}$, soma de bases trocáveis; ${ }^{3} \mathrm{t}$, capacidade de troca catiônica efetiva, ${ }^{4} \mathrm{~T}$, capacidade de troca de cátions a pH 7,$0 ;{ }^{5} \mathrm{~V}$, índice de saturação por bases; ${ }^{6} \mathrm{~m}$, índice de saturação por alumínio; ${ }^{7} \mathrm{SE}$, superfície específica. 
- oxídicos, com $\mathrm{Ki}>0,75$ e $\mathrm{Kr} \leq 0,75$ ou gibbsíticos-oxídicos, onde $\mathrm{Ki} \leq 0,75$ e $\mathrm{Kr} \leq 0,75$. Com base nesta análise, o LVdf é classificado como caulinitico-oxídico, o que corrobora com os dados obtidos no difratograma de Raios-X (Figura 1).

Já o MTo é uma classe de solo caracterizada por possuir características diferenciais. Fisicamente são solos mais rasos, mais susceptíveis à erosão e com presença de minerais expansíveis, o que torna o manejo físico desses solos mais difícil. Quimicamente apresentam teores bem superiores de cátions trocáveis, com pre-

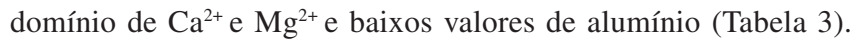
São solos normalmente pouco coloridos, bem a imperfeitamente drenados, tendo a presença de A chernozênico sobrejacente ao horizonte B textural (Bt), que apresenta argila de alta atividade, como a esmectita, sendo que este, aparentemente, apresenta-se em maior proporção que a caulinita conforme visto no difratograma de Raios-X (Figura 2).

Pelo difratograma de Raios X (Figura 2), a esmectita foi identificada neste solo por meio de reflexões a 1,430 nm que se expandiram quando na presença de $\mathrm{Mg}^{2+}$. Quando saturadas com $\mathrm{K}^{+}$e submetidas aos tratamentos térmicos $\left(25,110\right.$ e $\left.550^{\circ} \mathrm{C}\right)$, verificou-se o colapso e redução do espaçamento basal referente à esmectita. Com o aquecimento a $500^{\circ} \mathrm{C}$, além do colapso da estrutura, houve um deslocamento do pico para $1,0 \mathrm{~nm}$.

$\mathrm{O}$ alto valor de Ki deste solo (Tabela 2) indica que este apresenta intemperismo intermediário. ${ }^{18}$ Além disso, apresenta argilominerais 2:1 quando o valor de Ki é superior a 2,2, ${ }^{19}$ o que corrabora com os dados obtidos no difratograma de Raios-X (Figura 2).

\section{Experimento de sorção}

Na Tabela 4 encontra-se o resumo da análise de variância (ANAVA) para os valores de Kd, obtidos do experimento de sorção, nas concentrações de 20 e $40 \mu \mathrm{mol} \mathrm{L}{ }^{-1}$ de tiametoxam, em função das variáveis solo, ácidos orgânicos (AO) e concentração de ácidos orgânicos.

Tabela 4. Resumo da análise de variância para Kd nas concentrações de 20 e $40 \mu \mathrm{mol} \mathrm{L}^{-1}$ em função das variáveis solo, ácido orgânico e concentração de ácido orgânico

\begin{tabular}{lccc}
\hline \multirow{2}{*}{ Fonte de Variação } & GL & \multicolumn{2}{c}{ Quadrado Médio e sua significância } \\
\cline { 3 - 4 } & 1 & $\mathrm{Kd}\left(20 \mu \mathrm{mol} \mathrm{L} \mathrm{L}^{-1}\right)$ & $\mathrm{Kd}\left(40 \mu \mathrm{mol} \mathrm{L}^{-1}\right)$ \\
\hline Solo & 2 & $0,01^{\mathrm{NS}}$ & $17,77^{*}$ \\
AO & 2 & $0,09 *$ & $0,04^{\mathrm{NS}}$ \\
Conc. AO & 2 & $0,05^{\mathrm{NS}}$ & $0,04^{\mathrm{NS}}$ \\
Solo x AO & 2 & $0,28 *$ & $0,01^{\mathrm{NS}}$ \\
Solo x Conc. AO & 4 & $0,01^{\mathrm{NS}}$ & $0,10^{*}$ \\
AO x Conc. AO & 4 & $0,04^{\mathrm{NS}}$ & $0,02^{\mathrm{NS}}$ \\
Solo x Conc AO x AO & 36 & 0,66 & $0,02^{\mathrm{NS}}$ \\
resíduo & & 12,35 & 0,02 \\
\hline CV $(\%)$ & &
\end{tabular}

$*(\mathrm{p}<0,05) ;{ }^{\text {NS }}$ não significativo, pelo Teste de $\mathrm{F}$.

Segundo ANAVA, os resultados de Kd com tiametoxam em ambas as concentrações mostraram-se significativos para a interação dupla entre solo e concentração de ácido. Os resultados dessa interação para o tiametoxam na concentração de 20 e $40 \mu \mathrm{mol} \mathrm{L}^{-1}$ encontram-se na Tabela 5.

De acordo com a tabela 5 observa-se que, em todos os tratamentos, os solos estudados apresentaram comportamentos distintos, sendo
Tabela 5. Valores médios de $\mathrm{Kd}\left(\mathrm{L} \mathrm{kg}^{-1}\right)$ obtidos a partir da concentração de 20 e $40 \mu \mathrm{mol} \mathrm{L}{ }^{-1}$ de TMX

\begin{tabular}{ccrcr}
\hline \multirow{2}{*}{$\begin{array}{c}\text { Concentração AO } \\
\left(\mu \mathrm{mol} \mathrm{L}^{-1}\right)\end{array}$} & \multicolumn{2}{c}{$\mathrm{Kd}\left(20 \mu \mathrm{mol} \mathrm{L}^{-1}\right)$} & \multicolumn{2}{c}{$\mathrm{Kd}\left(40 \mu \mathrm{mol} \mathrm{L}^{-1}\right)$} \\
\cline { 2 - 5 } & $\mathrm{LVdf}$ & Mto & LVdf & Mto \\
\hline 0 & $0,687 \mathrm{Ba}$ & $1,381 \mathrm{Ab}$ & $0,621 \mathrm{Aa}$ & $1,599 \mathrm{Ab}$ \\
200 & $0,634 \mathrm{Ba}$ & $1,721 \mathrm{Bb}$ & $0,570 \mathrm{Aa}$ & $1,834 \mathrm{Bb}$ \\
400 & $0,501 \mathrm{Aa}$ & $1,651 \mathrm{Bb}$ & $0,586 \mathrm{Aa}$ & $1,786 \mathrm{Bb}$ \\
\hline
\end{tabular}

Médias seguidas pela mesma letra minúscula na linha e maiúscula na coluna pertencem a um mesmo grupo pelo teste de Skott-Knott a nível de 5\% de probabilidade.

que o MTo apresentou maior capacidade de sorção do tiametoxam em comparação com o LVdf.

A sorção é dependente não somente da carga da superfície, mas também da área superficial. A quantidade de material sorvido é diretamente proporcional à superfície específica, assim a sorção será grande se a área superficial for grande. ${ }^{20}$

Isso explica o maior valor de Kd encontrado no MTo, uma vez que, de acordo com os difratogramas de Raios X (Figura 2), este solo possui presença definida de argilominerais expansivos, que contribui significativamente para valores maiores de superfície especifica, de $526 \mathrm{~m}^{2} \mathrm{~g}^{-1}$, em comparação com LVdf que apresenta superfície especifica bastante inferior, $108 \mathrm{~m}^{2} \mathrm{~g}^{-1}$, em virtude da sua mineralogia. Esses valores contrastantes de superfície específica é consequência da mineralogia mais ativa e menor tamanho de partícula de minerais encontrados no MTo.

Em relação à presença de ácidos orgânicos, estes tiveram comportamento distinto entre os solos. Observa-se que, para o MTo, esta adição contribuiu favoravelmente para o aumento da sorção do tiametoxam, sendo que o Kd obtido a partir das concentrações de 200 e $400 \mu \mathrm{mol} \mathrm{L}{ }^{-1}$ não diferiram estatisticamente entre si. Isto ocorre, provavelmente, pelo aumento do espaçamento basal, uma vez que compostos orgânicos contribuem para uma maior expansão das entrecamadas, o que, consequentemente, permite que mais moléculas de tiametoxam ocupem esse espaço. ${ }^{14}$ Essa expansão do espaçamento basal de argilominerais pela adição de compostos orgânicos já foi observada em alguns trabalhos ${ }^{21,22}$ envolvendo adsorção de ácido aspártico em montmorilonita e de ácidos carboxílicos, entre eles os ácidos oxálico e acético, em argilominerais 2:1 expansíveis.

Além disso, a presença de ácidos orgânicos nas entrecamadas aumenta o número de sítios ativos o que permite que as moléculas de tiametoxam interajam não somente com as moléculas de água e oxigênios presentes nas entrecamadas, bem como com os hidrogênios e oxigênios dos ácidos orgânicos, possivelmente por ligação de hidrogênio.

Já para o LVdf, os valores de Kd com tiametoxam na concentração de $20 \mu \mathrm{mol} \mathrm{L}{ }^{-1}$ e na presença de ácido orgânico apresentou valores estatisticamente distintos apenas para a concentração de $400 \mu \mathrm{mol}$ $\mathrm{L}^{-1}$, sendo que este influenciou desfavoravelmente a sorção do tiametoxam. Isto se deve, provavelmente, à competição entre o tiametoxam e os ácidos pelos sítios ativos da fração mineral do LVdf.

Alguns autores estudaram a formação de complexos entre os grupos funcionais dos ácidos orgânicos e os hidróxidos da superfície de óxidos de ferro e concluíram que, com o decréscimo do valor do $\mathrm{pH}$, os sítios da superfície dos óxidos e hidróxidos ficam com carga neutra ou positiva $\left(\mathrm{OH}^{0} \mathrm{ou} \mathrm{OH}_{2}^{+}\right)$. Neste caso, a ligação ferro-oxigênio fica mais fraca, em virtude da densidade de elétrons da ligação, e os oxigênios, na forma de $\mathrm{OH}^{0}$ ou $\mathrm{OH}_{2}^{+}$, são trocados com os grupos funcionais do ácido orgânico de forma específica. ${ }^{23}$

A afinidade entre o adsorbato e superfícies adsorventes variam de acordo com vários fatores, entre eles a concentração do adsorbato. ${ }^{24}$ 
Em concentração maior de ácido orgânico este começou a competir com o tiametoxam pela ocupação dos sítios ativos, o que levou a diminuição da adsorção do agrotóxico.

Dessa forma, pode-se dizer que, devido às reações dos ácidos orgânicos com as hidroxilas da superfície dos minerais, estas estariam menos disponíveis para reagirem com o tiametoxam e isso explicaria o menor valor de Kd encontrado para o LVdf na concentração de $400 \mu \mathrm{mol} \mathrm{L}^{-1}$. Em contrapartida, isso não foi observado para a concentração de $200 \mu \mathrm{mol} \mathrm{L}{ }^{-1}$. Provavelmente, por estar em menor concentração, não houve competição entre o ácido orgânico e o tiametoxam pelos sítios ativos, o que permitiu que a molécula do agrotóxico tivesse maior interação com as superfícies dos minerais.

Já para este mesmo solo, os valores de Kd com tiametoxam na concentração de $40 \mu \mathrm{mol} \mathrm{L}^{-1}$ e na presença de ácidos orgânicos nas concentrações de 200 e $400 \mu \mathrm{mol} \mathrm{L}^{-1}$ e sem ácido não se diferiram estatisticamente, o que indica que, para este caso, a presença de ácido orgânico, nestas concentrações, não influenciou a sorção do tiametoxam. Isto ocorre devido ao aumento da concentração do tiametoxam, que provavelmente diminui a competição pelos sítios ativos do LVdf e, como resultado, favorece sua ligação com a superfície dos minerais.

É importante ressaltar que para o experimento de sorção, com ambas as concentrações de tiametoxam, não houve diferença estatística ( $p>0,05)$ entre os tipos de ácidos (Tabela 4), ou seja, os ácidos cítrico, quínico e oxálico tiveram comportamentos semelhantes na sorção do tiametoxam em ambos os solos.

\section{Experimento de dessorção}

Na tabela 6 encontra-se o resumo da análise de variância (ANAVA) para os valores de Kd de dessorção nas concentrações de 20 e $40 \mu \mathrm{mol} \mathrm{L}^{-1}$ de tiametoxam, em função das variáveis solo, ácidos orgânicos $(\mathrm{AO})$ e concentração de ácidos orgânicos.

Tabela 6. Resumo da análise de variância para Kd de dessorção nas concentrações de 20 e $40 \mu \mathrm{mol} \mathrm{L}^{-1}$ em função das variáveis solo, ácido orgânico e concentração de ácido orgânico

\begin{tabular}{lccc}
\hline \multirow{2}{*}{ Fonte de Variação } & GL & \multicolumn{2}{c}{ Quadrado Médio e sua significância } \\
\cline { 3 - 4 } & & $\mathrm{Kd}\left(20 \mu \mathrm{mol} \mathrm{L}{ }^{-1}\right)$ & $\mathrm{Kd}\left(40 \mu \mathrm{mol} \mathrm{L}^{-1}\right)$ \\
\hline Solo & 1 & $518,17^{*}$ & $176,16^{*}$ \\
AO & 2 & $3,80^{\mathrm{NS}}$ & $4,00^{\mathrm{NS}}$ \\
Conc. AO & 2 & $7,15^{\mathrm{NS}}$ & $1,28^{\mathrm{NS}}$ \\
Solo x AO & 2 & $3,05^{\mathrm{NS}}$ & $0,50^{\mathrm{NS}}$ \\
Solo x Conc. AO & 2 & $20,27^{*}$ & $7,34^{*}$ \\
AO x Conc. AO & 4 & $5,14^{\mathrm{NS}}$ & $2,14^{\mathrm{NS}}$ \\
Solo x Conc AO x AO & 4 & $1,17^{\mathrm{NS}}$ & $0,30^{\mathrm{NS}}$ \\
resíduo & 36 & 2,49 & 1,67 \\
\hline CV $(\%)$ & & 30,33 & 19,59
\end{tabular}

$*(\mathrm{p}<0,05) ;{ }^{\text {Ns }}$ não significativo, pelo Teste de $\mathrm{F}$.

Segundo ANAVA os resultados de Kd de dessorção com tiametoxam em ambas as concentrações mostraram-se significativos para a interação dupla entre solo e concentração de ácido. Os resultados dessa interação para o tiametoxam nas concentrações de 20 e $40 \mu \mathrm{mol} \mathrm{L}^{-1}$ encontram-se na Tabela 7.

Observa-se que, para todos os tratamentos, o LVdf apresentou menor Kd para dessorção quando comparado ao MTo, ou seja, menor quantidade de tiametoxam permaneceu sorvida no LVdf
Tabela 7. Valores de Kd para dessorção $\left(\mathrm{L} \mathrm{kg}^{-1}\right)$ obtidos a partir da concentração de $20 \mu \mathrm{mol} \mathrm{L}{ }^{-1}$ de TMX

\begin{tabular}{ccccc}
\hline \multirow{2}{*}{$\begin{array}{c}\text { Concentração AO } \\
(\mu \mathrm{mol} \mathrm{L})\end{array}$} & \multicolumn{2}{c}{$\mathrm{Kd}\left(20 \mu \mathrm{mol} \mathrm{L}^{-1}\right)$} & \multicolumn{2}{c}{$\mathrm{Kd}\left(40 \mu \mathrm{mol} \mathrm{L}^{-1}\right)$} \\
\cline { 2 - 5 } & LVdf & Mto & LVdf & Mto \\
\hline 0 & $2,416 \mathrm{Aa}$ & $6,581 \mathrm{Ab}$ & $5,210 \mathrm{Aa}$ & $7,362 \mathrm{Ab}$ \\
200 & $1,215 \mathrm{Aa}$ & $9,614 \mathrm{Bb}$ & $4,627 \mathrm{Aa}$ & $8,869 \mathrm{Bb}$ \\
400 & $2,695 \mathrm{Aa}$ & $8,717 \mathrm{Bb}$ & $5,219 \mathrm{Aa}$ & $8,984 \mathrm{Bb}$ \\
\hline
\end{tabular}

Médias seguidas pela mesma letra minúscula na linha e maiúscula na coluna pertencem a um mesmo grupo pelo teste de Skott-Knott a nível de 5\% de probabilidade.

após a dessorção. Isso é atribuído ao fato da sorção do tiametoxam neste solo ser relativamente mais fraca, uma vez que essa retenção ocorreu apenas em superfície externa, em virtude da mineralogia deste solo (Figura 1). Dessa forma, o rompimento da ligação é mais favorecido.

Quanto à adição de ácidos orgânicos, nas concentrações de 200 e $400 \mu \mathrm{mol} \mathrm{L}{ }^{-1}$, estas não influenciaram a dessorção do tiametoxam no LVdf. Estatisticamente, os valores de Kd de dessorção com e sem ácido não diferiram entre si. Esperava-se que o Kd de dessorção do tiametoxam com ácido na concentração de $400 \mu \mathrm{mol} \mathrm{L} \mathrm{L}^{-1}$ fosse inferior, uma vez que ocorreu uma menor sorção inicial para este tratamento (Tabela 5). Porém, a presença de ácidos orgânicos ligados à superfície parece ter provocado enfraquecimento das ligações do tiametoxam, o que consequentemente proporcionou uma alta taxa de dessorção. Sendo assim, os valores de dessorção para todos os tratamentos não foram estatisticamente diferentes neste solo.

Em contrapartida, para o MTo, a adição de ácidos orgânicos em ambas as concentrações diminuiu a dessorção do tiametoxam, ou seja, o produto ficou mais sorvido ao solo quando na presença de ácidos orgânicos. Isto ocorreu em virtude do aumento de sítios ativos pelos ácidos, de modo que o tiametoxam ligou-se mais fortemente ao mineral, dificultando seu retorno para a solução.

É importante observar que, em geral, os valores de Kd para a dessorção mostraram-se superiores aos obtidos no experimento de sorção (Tabela 5). Isso mostra que mesmo havendo dessorção do produto, esse retorno à solução não é completo, ficando parte do produto retido nos solos, fenômeno chamado de histerese.

\section{Análise no infravermelho}

As Figuras 3 e 4 mostram os espectros de infravermelho obtidos após o experimento de sorção, para cada solo, sem e com adição de $0,5 \mu \mathrm{mol} \mathrm{L}{ }^{-1}$ de cada ácido orgânico.

Analisando os espectros do LVdf (Figura 3), observa-se bandas nas regiões de 3.697 e $3.622 \mathrm{~cm}^{-1}$ que podem ser atribuídas ao estiramento vibracional de grupo hidroxila interna e externo da caulinita, respectivamente. Outra banda característica de caulinita ocorre na região entre $1.100 \mathrm{a} 830 \mathrm{~cm}^{-1}$ referente à ligação Si-O. Essas bandas foram identificadas no espectro como 1100, 1006 $\mathrm{cm}^{-1}$. Bandas nas regiões de 3.528, 3.444, 3.378 e $912 \mathrm{~cm}^{-1}$ podem ser atribuídas à gibbsita. A goethita tem absorção em, aproximadamente, $790 \mathrm{~cm}^{-1}$, referente à ligação $\mathrm{Fe}-\mathrm{O}-\mathrm{OH}$. A hematita tem absorção em número de onda abaixo de $750 \mathrm{~cm}^{-1}$, indicativo de ligação $\mathrm{Fe}-\mathrm{O} .^{25,26}$

Os espectros do MTo (Figura 4) também apresentam bandas nas regiões de 3697 e $3622 \mathrm{~cm}^{-1}$, referentes as estiramento vibracional de grupo hidroxila interno e externo da caulinita, além de banda na região de 997 e $912 \mathrm{~cm}^{-1}$, referente à ligação Si-O da caulinita. Apresentam também bandas na região de $753 \mathrm{~cm}^{-1}$ referente à goethita e bandas com número de onda abaixo de $750 \mathrm{~cm}^{-1}$, indicativo 

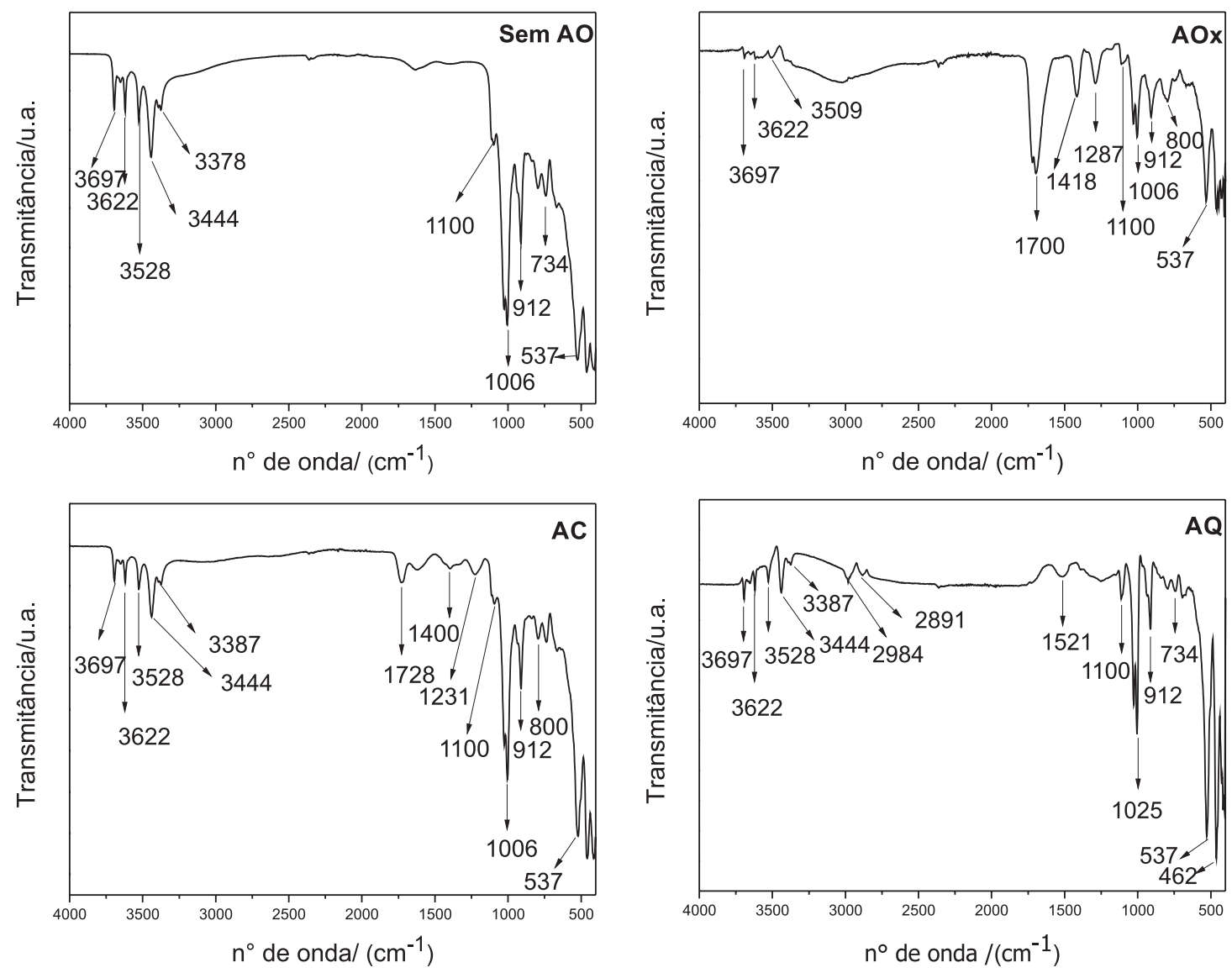

Figura 3. Espectro de ATR-FTIR para LVdf, sem e com adição de ácidos orgânicos 0,5 mol L-1 após o experimento de sorção
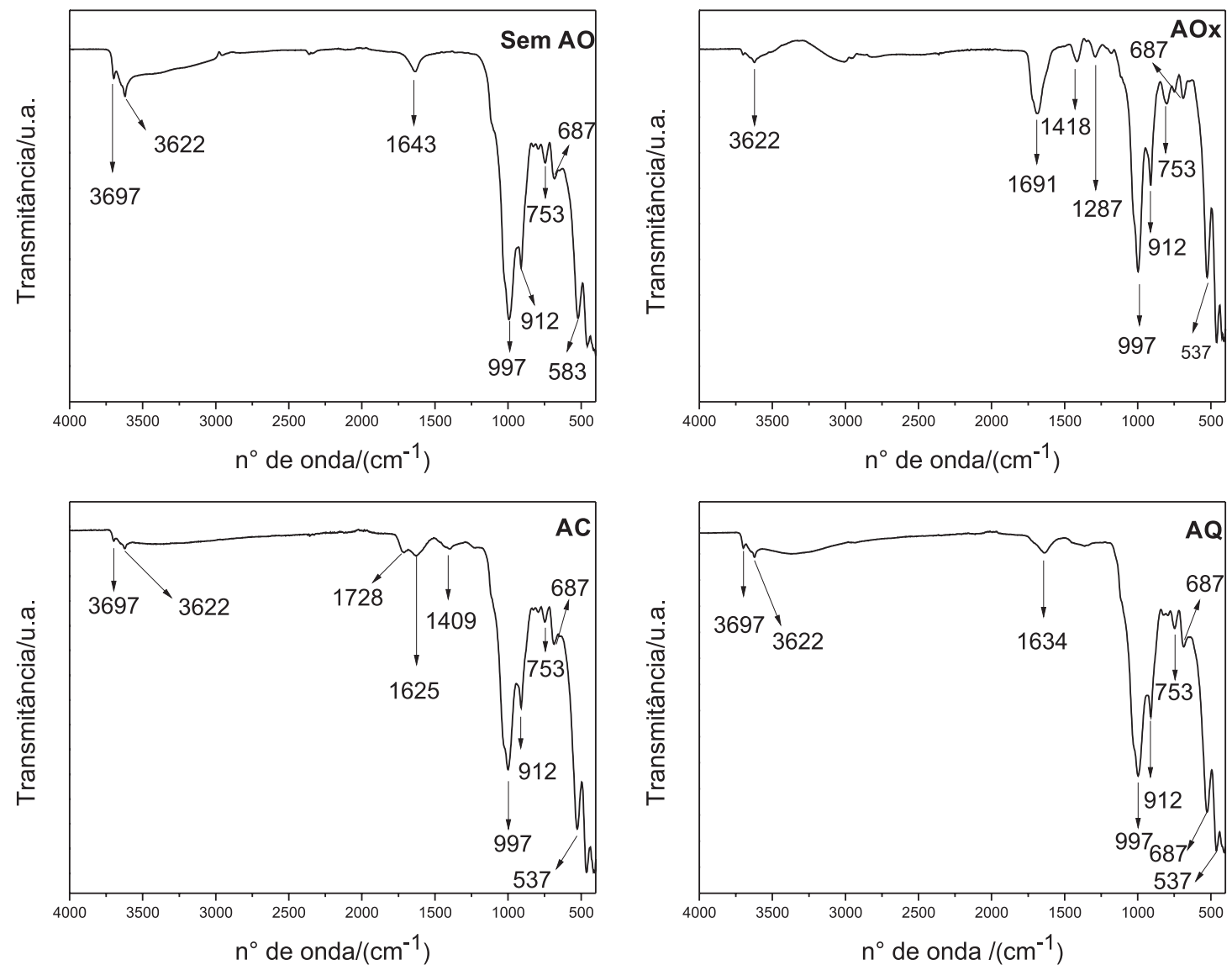

Figura 4. Espectro de ATR-FTIR para MTo, sem e com adição de ácidos orgânicos 0,5 mol $\mathrm{L}^{-1}$, após o experimento de sorção 
de ligação $\mathrm{Fe}-\mathrm{O}$ de hematita. Este ainda apresenta banda na região entre $1691 \mathrm{e} 1625 \mathrm{~cm}^{-1}$, referentes à deformação angular da água de hidratação presente na região entrecamadas, característica de argilominerais expansivos. ${ }^{25,26}$

Além dessas bandas, em ambas as figuras observam-se bandas características de ácidos carboxílicos, como nas regiões de 3400-2400 $\mathrm{cm}^{-1}$, referente ao estiramento $\mathrm{O}-\mathrm{H}, 1730-1700 \mathrm{~cm}^{-1}$ correspondente ao estiramento $\mathrm{C}=\mathrm{O}, 1440-1400 \mathrm{~cm}^{-1}$ para deformação $\mathrm{O}-\mathrm{H}$ e 1320 $1210 \mathrm{~cm}^{-1}$ indicativo de estiramento C-O.

Além disso, nota-se no MTo um deslocamento da banda na região de $1643 \mathrm{~cm}^{-1}$, característica da deformação angular da água de hidratação, quando na presença de ácidos orgânicos. Isto se deve provavelmente à intercalação dos ácidos na região entrecamadas de argilominerais 2:1 expansíveis. Dessa forma, fica evidente a presença de ácidos orgânicos no espaço intermicelar, o que consequentemente favorece a sorção de tiametoxam nesse solo.

É possível verificar, pela análise do espectro da testemunha (sem AO) (Figuras 3 e 4), que houve redução de bandas típicas dos minerais na presença de ácidos orgânicos. Segundo alguns autores, adsorção de ligantes orgânicos na superfície de minerais regula diversas reações químicas ambientais, tal como a dissolução. ${ }^{27}$

Dessa forma, a redução das bandas dos espectros com adição de ácidos, provavelmente, se deve à decomposição dos minerais pela formação de complexos com os metais. ${ }^{28}$ Isso evidencia a ocupação dos sítios ativos pelos ácidos orgânicos. Dessa forma, a ligação do tiametoxam com a superfície dos minerais, no LVdf, fica comprometida em virtude da competição entre as moléculas dos ácidos e do tiametoxam pelos sítios ativos.

Nas Figuras 5 e 6 encontram-se os espectros obtidos após o experimento de dessorção com ácidos na concentração de $0,5 \mathrm{~mol} \mathrm{~L}^{-1}$.

Observa-se que os espectros de ambos os solos, após a dessorção,
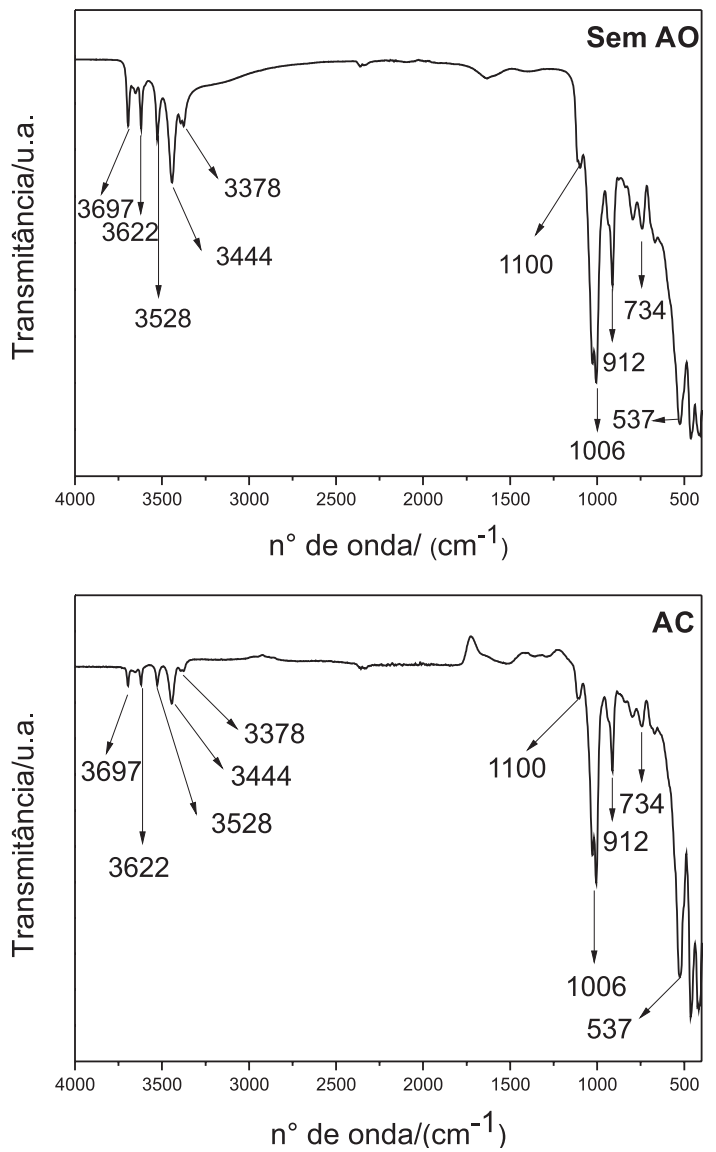

não apresentaram nenhuma banda referente a grupos funcionais de ácidos carboxílicos, exceto para o ácido quínico no LVdf.

As fortes interações entre o ligante e o metal na superfície induz polarização das ligações entre o átomo metálico e os átomos de oxigênio na estrutura mineral. Essa polarização enfraquece o vínculo, o que permite o retorno para a solução. ${ }^{29}$ Isso possivelmente explica a ausência de bandas características de ácidos carboxílicos nos solos após a dessorção.

Já o ácido quínico, por formar um complexo monodentado, ou seja, apenas uma ligação de oxigênio com a superfície mineral, possui uma densidade eletrônica menor, em comparação com complexos bidentados, como as ligações entre os ácidos oxálico e cítrico e o metal. Dessa forma, não há polarização das ligações e, consequentemente, a dissolução dos minerais não é promovida. Por isso é possível notar a permanência de bandas referentes ao estiramento $\mathrm{O}-\mathrm{H}$, característicos de ácidos carboxílicos (Figura 5).

Assim, em relação ao processo de dessorção, acredita-se que a presença de ácidos orgânicos, no LVdf, não influencia a dessorção do tiametoxam, uma vez que, durante esse processo, os ácidos orgânicos não permanecem na superfície do mineral, com exceção do ácido quínico. Dessa forma, as amostras com e sem ácidos orgânicos atuam de maneira semelhante. Já no MTo a presença de ácidos orgânicos diminui a dessorção do tiametoxam em virtude da permanência dos ácidos entrecamadas após o processo de dessorção. Essa permanência é evidenciada pelo deslocamento da banda na região de $1643 \mathrm{~cm}^{-1}$, característica de deformação angular da água de hidratação presente nas entrecamadas (Figura 6). Logo, como a sorção do tiametoxam, no MTo, é favorecida na presença de ácidos orgânicos, e estes permanecem nas entrecamadas após o processo de dessorção, o tiametoxam tende a permanecer no MTo, mesmo após a dessorção.
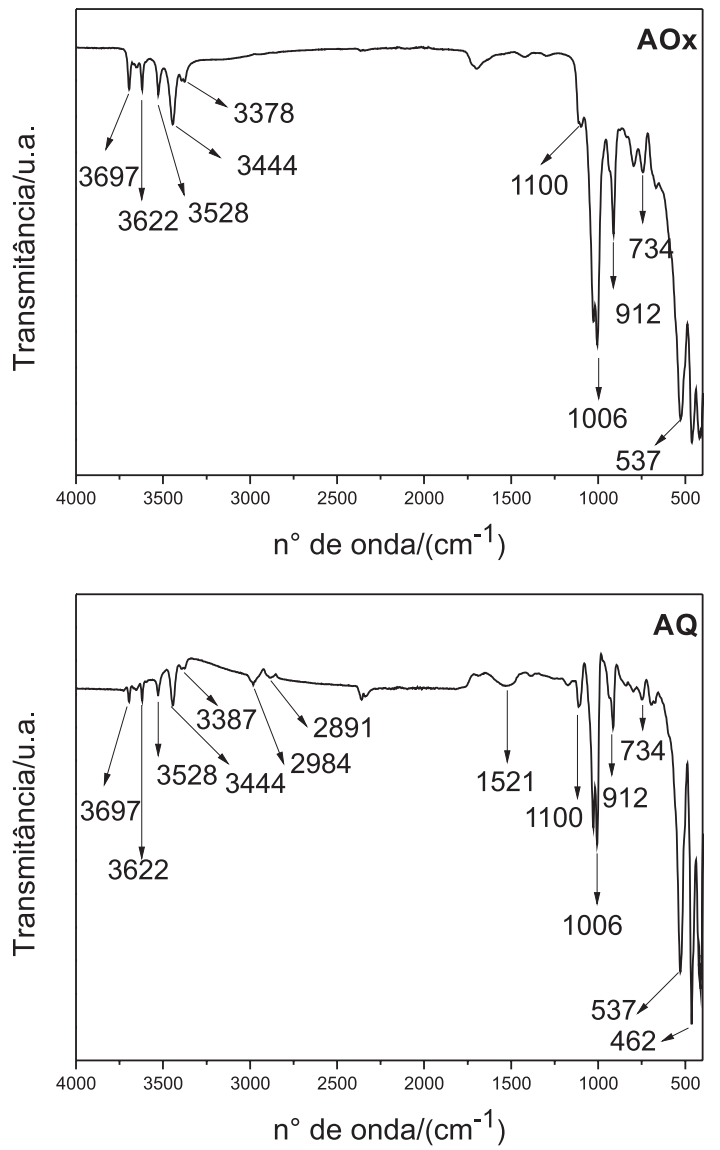

Figura 5. Espectro de ATR-FTIR para LVdf, sem e com adição de ácidos orgânicos 0,5 mol $\mathrm{L}^{-1}$, após o experimento de dessorção 

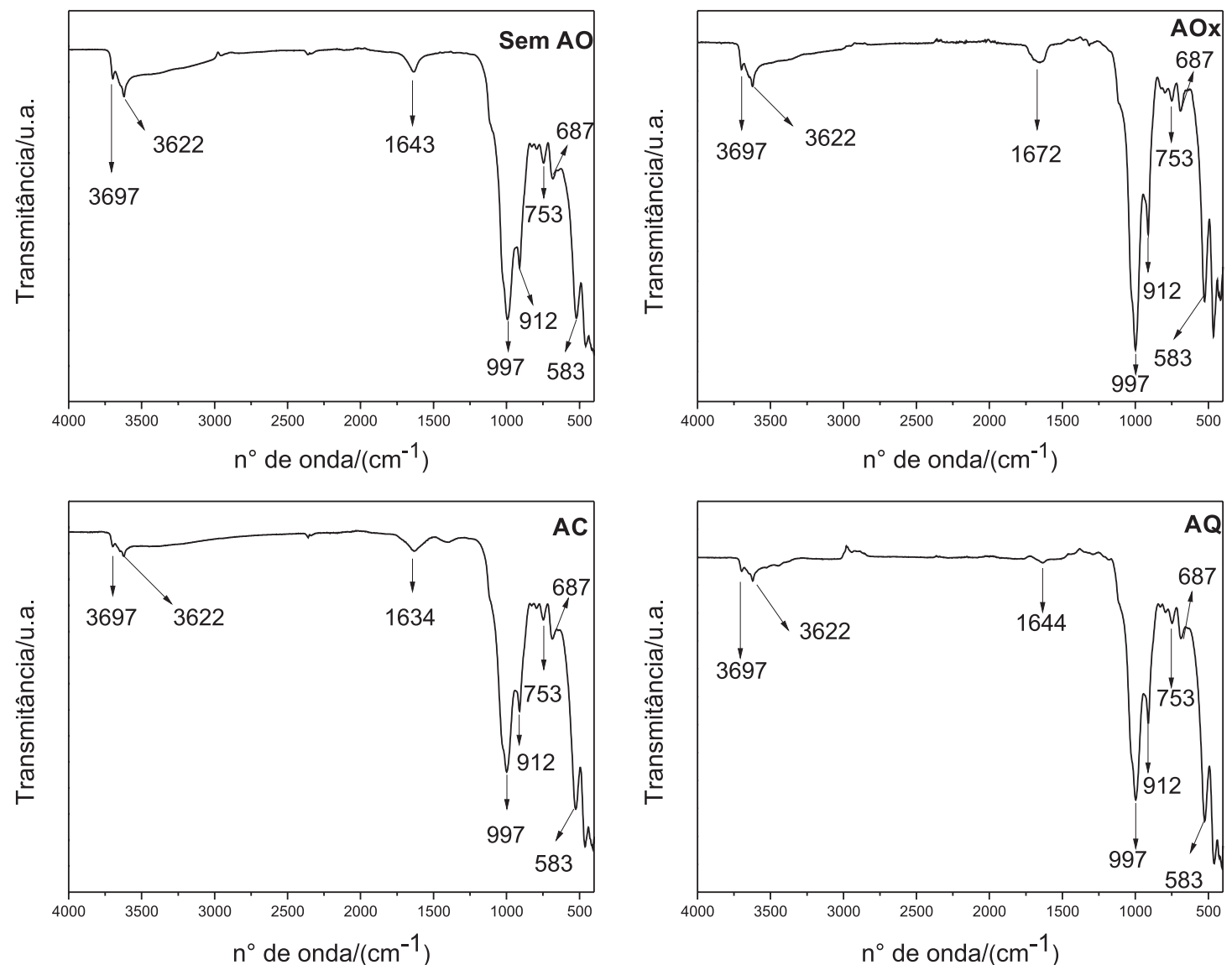

Figura 6. Espectro de ATR-FTIR para MTo, sem e com adição de ácidos orgânicos 0,5 mol $\mathrm{L}^{-1}$, após o experimento de dessorção

\section{CONCLUSÃO}

O MTo foi o solo que apresentou maior sorção do tiametoxam, em virtude da presença de argilominerais expansivos e consequente alta superfície específica. Quanto à presença de ácidos orgânicos, estes influenciaram favoravelmente a sorção do tiametoxam no MTo em ambas as concentrações do agrotóxico. Além disso, a presença desses ácidos diminuiu a dessorção do tiametoxam. Assim, o uso de agrotóxicos nestes solos, associado à presença de ácidos, favorece a permanência do agrotóxico no solo, diminuindo os impactos ambientais causados por seu uso.

No LVdf o valor de Kd, com a presença de ácidos orgânicos na concentração de $400 \mu \mathrm{mol} \mathrm{L}{ }^{-1}$ e tiametoxam na concentração de $20 \mu \mathrm{mol} \mathrm{L}{ }^{-1}$, foi inferior à testemunha, evidenciando a competição entre o agrotóxico e os ácidos pelos sítios ativos dos minerais. Assim, neste caso, a presença de ácidos orgânicos desfavorece a sorção do tiametoxam, o que contribui para aumento da contaminação ambiental. Já na concentração de $40 \mu \mathrm{mol} \mathrm{L}^{-1}$ de tiametoxam a presença de ácidos orgânicos não interferiu na sorção do mesmo.

Não houve efeito da presença de ácidos orgânicos na dessorção do tiametoxam no LVdf.

Não houve diferença estatística entre os ácidos orgânicos empregados neste trabalho.

Através do HPLC-UV foi possível quantificar pequenas concentrações de tiametoxam e, dessa forma, melhor compreender a sorção e dessorção desse agrotóxico no solo.

Foi possível compreender a dinâmica dos ácidos orgânicos, na concentração de $0,5 \mathrm{~mol} \mathrm{~L}^{-1} \mathrm{com}$ as partículas minerais do solo, através da análise no infravermelho. Com essa técnica ficou evidenciada a ocupação dos sítios ativos dos minerais, presentes no LVdf, pelos ácidos orgânicos, além da intercalação desses ácidos na região intermicelar de minerais 2:1 expansíveis presentes no MTo.

\section{REFERÊNCIAS}

1. http://www.sindag.com.br/noticia.php?News_ID=2256, acessada em Agosto 2012.

2. Fenik, J.; Tankiewicz, M.; Biziuk, M.; Trends Anal. Chem. 2011, 30, 814.

3. Lambropoulou, D. A.; Albanis, T. A.; J. Biochem. Bioph. Methods. 2007, 70, 195.

4. Castro, N. R. A.; Tese de Doutorado, Universidade Federal de Lavras, Brasil, 2005.

5. Marschner, H.; Mineral nutrition of higher plants, $2^{\text {th }}$ ed., Academic Press: San Diego, 1995.

6. Jones, D. L.; Plant and Soil 1998, 205, 25.

7. Schwab, A. P.; Zhu, D. S.; Banks, M. K.; Chemosphere 2008, 72, 986.

8. Ding, Q.; Wu, H. L.; Xu, Y.; Guo, L. J.; Liu, K.; Gao, H. M.; Yang, H.; J. Hazard. Mater. 2011, 190, 823.

9. Urzedo, A. P. F. M.; Rigitano, R. L. O.; Lima, J. M.; Castro, N. R. A.; Pesticida: Revista de Ecotoxicologia e Meio Ambiente 2006, $16,71$.

10. Day, P. R. Em Methods of Soil Analysis; Black, C. A., ed.; American Society of Agronomy: Madison, 1965.

11. Empresa Brasileira de Pesquisa Agropecuária. Manual de métodos de análises de solo, $2^{\mathrm{a}}$ ed., CNPS: Rio de Janeiro, 1997.

12. Oliveira, V. S.; Lima, J. M.; Carvalho, R. F.; Rigitano, R. L. O.; Quim. Nova. 2009, 32, 1432.

13. Ferreira, D. F.; Programa Sisvarexe: sistema de análise de variância; Universidade Federal de Lavras, Brasil, 1999.

14. Empresa Brasileira de Pesquisa Agropecuária. Sistema Brasileiro de Classificação de Solos, $2^{\mathrm{a}}$ ed., Rio de Janeiro, 2006. 
15. Fontes, M. P. F.; Camargo, O. A.; Sposito, G.; Scientia Agricola 2001, $58,627$.

16. Rodrigues, T. E.; Klamt, E.; Rev. Bras. Ci. Solo 1978, 2, 132.

17. Vidal -Torrado, P.; Macias, F.; Calvo, R.; Carvalho, S. G.; Silva, A. C.; Rev. Bras. Ci. Solo 2006, 30, 523.

18. Araújo, E. F.; Dissertação de Mestrado, Universidade Federal do Rio Grande do Sul, Brasil, 2011.

19. Mello, V. F.; Costa, L. M.; Barros, N. F.; Fontes, M. P. F.; Novais, R. F.; Rev. Bras. Ci. Solo 1995, 19, 159.

20. Tan, K. H.; Principles of soil chemistry, $3^{\text {rd }}$ ed., Dekker: New York, 1998.

21. Naidja, A.; Huang, P. M.; Appl. Clay Sci. 1994, 9, 265.

22. Kubicki, J . D.; Schroeter, L. M.; Itoh, M. J.; Nguyen, B. N.; Apytz, S. E.; Geochim. Cosmochim. Acta 1999, 63, 2709.
23. Evanko, C. R.; Dzombak, D. A.; Environ. Sci. Technol. 1998, 32, 2846.

24. Melo, V. F.; Alleoni, L. R. F.; Química e mineralogia do solo, $2^{\text {nd }}$ ed., Sociedade Brasileira de Ciência do Solo: Viçosa, 2009.

25. Henriques, B. A.; Tese de Doutorado, Universidade Federal de Minas Gerais, Brasil, 2012.

26. Makó, E.; Senkár, Z.; Kristóf, J.; Vágvölgyi, V.; J. Colloid Interface Sci. 2006, 294, 362.

27. Furrer, G.; Stumm, W.; Geochim. Cosmochim. Acta 1986, 50, 1847.

28. Kämpf, N.; Curi, N.; Marques, J. J.; Química e mineralogia do solo, $1^{\mathrm{a}}$ ed., Sociedade Brasileira de Ciência do Solo: Viçosa, 2009.

29. Duckworth, O. W.; Martin, S.T.; Pergamon 2001, 65, 4289. 